\title{
Fetal Lung Development in Male and Female Nonhuman Primates
}

\author{
ROBERT H. PERELMAN, MICHAEL J. ENGLE, MARI PALTA, JOSEPH W. KEMNITZ, AND \\ PHILIP M. FARRELL \\ Department of Pediatrics, University of Wisconsin and Regional Primate Research Center, \\ Madison, Wisconsin 53715
}

\begin{abstract}
Indices of lung maturation were assessed in 58 rhesus fetuses at five gestational ages during the last trimester of nonhuman primate pregnancy to determine whether fetal sex influences lung maturation. In addition to analysis of whole lung phospholipids, glycogen, protein, DNA, and pressure-volume curves surfactant fraction phosphatidylcholine (PC) was quantitated following isolation by sucrose gradient centrifugation and a combination of predictors were assessed by all possible subsets regression to attain a composite "maturity index." For the total population, there was a uniform progression in physical growth characteristics, lung destensibility and stability and phospholipids with advancing gestation. The quantitative change in surfactant fraction PC concentration for both sexes was considerably greater than that observed for whole lung PC between 135 days gestation and term. Further, the increase in surfactant PC occurred in association with improving lung destensibility and deflation stability prior to maximum changes in the whole lung $\mathrm{PC}$ or disaturated PC concentration. There were no statistically discernible differences in biochemical or physiological assessment between sexes at any gestational age. These data in nonhuman primates suggest that documented differences in survival from the respiratory distress syndrome between males and females do not result from a discordance in lung maturation as a function of time throughout the last trimester of gestation. (Pediatr Res 20: 987-991, 1986)
\end{abstract}

\section{Abbreviations}

RDS, respiratory distress syndrome

PC, phosphatidylcholine

SM, sphingomyelin

lysoPC, lysophosphatidylcholine

PI, phosphatidylinositol

PS, phosphatidylserine

PE, phosphatidylethanolamine

PG, phosphatidylglycerol

DSPC, disaturated PC

DHT, dihydrotestosterone

Despite significant technical advances in the care of premature human neonates, aggressive regionalization of perinatal health care services, and enhanced understanding of the pathobiology

Received March 21, 1986; accepted May 22, 1986.

Correspondence Robert H. Perelman, M.D., University of Wisconsin Perinatal Center-6C, 202 South Park Street, Madison, WI 53715

Supported in part by National Institutes of Health (NIH) Pulmonary SCOR Grant P50-HL-27358 and NIH Grant P51-RR-00167. Publication no. 25-027 of the Wisconsin Regional Primate Research Center. of newborn diseases, the RDS remains the leading cause of neonatal mortality in the United States (1). Additionally, epidemiologic surveys have noted increased morbidity and mortality from RDS in males as compared to females (2). The pathobiologic mechanisms for the greater mortality from RDS in male neonates has not been examined until recently.

Since insufficient amounts of pulmonary surfactant represent a primary factor contributing to clinical RDS and the attendant respiratory failure, a logical place to assess potential sex-related variation in mortality from the disease is the surfactant phospholipid biosynthetic system. Investigations involving experimental animals have provided contradictory data regarding the timecourse of fetal lung maturation in males versus females (3-8). Furthermore, administration of various exogenous substances including thyroid hormone, testosterone, estrogen, and corticosteroids can affect the timing of lung development. However, these agents probably do not represent the trigger mechanism for in vivo maturation. Whether documented differences in survival from RDS between males and females represent discordance in the timing of phospholipid synthesis, secretory mechanisms, or nonsurfactant protein interactions remains unclear. Moreover, if surfactant phospholipid concentrations and the progression of lung maturation in both sexes were similar other undelineated mechanisms may mediate differences in postnatal survival.

In this investigation the hypothesis tested, that there is a delay in the progression of lung development in the male fetus, is based on conventional thought derived from human epidemiologic surveys, in which the emphasis has been on fatal RDS, and on analysis of rat and rabbit fetuses after pharmacologic manipulations.

As one objective of ongoing multidisciplinary investigations, we have prospectively studied biochemical and physiologic indices of lung maturation in fetal nonhuman primates at key times in normal gestation to ascertain if discordances can be detected based on fetal gender. In this regard, the experimental approach not only allows comparison of pulmonary developmental indices between male and female fetuses grouped at discrete gestational ages, but also permits assessment of changes as a function of time throughout the last trimester of rhesus pregnancy. As part of this comprehensive approach, we have utilized a modified scheme of sucrose gradient centrifugation recently proved useful for the small scale preparation of a lung fraction enriched in the phospholipids most characteristic of pulmonary surfactant (9).

\section{METHODS}

Fifty-eight pregnant rhesus monkeys (Macaca mulatta) with conception dates known within plus or minus one day were given intramuscular ketamine hydrochloride $(10-15 \mathrm{mg} / \mathrm{kg}$; ParkeDavis, Detroit, MI) and nitrous oxide-oxygen (4:2 liter/min) inhalation anesthesia. After placental localization, the abdomen 
and uterus were appropriately incised to avoid the placenta and the lower fetal body segment delivered to the umbilicus. Subsequent to sampling fetal umbilical vessel blood, the cord was clamped and sodium heparin $(2 \mathrm{ml}, 50 \mathrm{U} / \mathrm{ml})$ and Pentobarbital $(3 \mathrm{ml}, 50 \mathrm{mg} / \mathrm{ml})$ were rapidly infused into the fetus. Immediately thereafter the cord was cut and the fetus delivered with a small surgical glove placed over the head to prevent potential air exchange. Fetal animals were delivered at approximately 125 , $135,145,155$, and 162 days gestation (term equals 165 days). A comprehensive description of animal care and experimental procedures has been reported elsewhere (10).

After breech delivery, the fetus was immediately transferred to a dissection table where crown-rump length and body weight were measured; after this, the abdominal aorta was incised to exsanguinate the animal. The body was then transected subdiaphragmatically, and the left diaphragm carefully opened from below. The left lung was deflected laterally with cotton swabs and the hilum clamped with a small curved forceps. The left lung was carefully removed, weighed as separate lobes, and distributed for biochemical studies, leaving the chest wall, mediastinum, and right lung intact. After tracheostomy, a plugged 3 to $4 \mathrm{~cm}$ segment of 5 or 8 French flexible catheter was placed endotracheally and pressure-volume studies were conducted in situ (11).

Extraction and comprehensive analysis of lung phospholipids were accomplished by established procedures (12-17) as detailed in a previous publication (18). In general, a chloroform:methanol $(2: 1 \mathrm{v} / \mathrm{v})$ extract was prepared and washed free of nonlipid contaminants by the method of Radin (12), and phospholipids were isolated by 2-dimensional thin-layer chromotography. An internal standard of $\left[{ }^{14} \mathrm{C}\right]$ dipalmitoyl $\mathrm{PC}$ was added to measure recoveries with each analysis and to assess the quality control of analytical procedures. Lipid extracts were plated on silica gel $\mathrm{H}$ and developed in the first direction in a solvent system of chloroform:methanol:water (65:45:5). After air drying for 10 min, the plates were rotated $90^{\circ}$ and developed in a second solvent system of tetrahydrofuran:methylal:methanol:2 $\mathbf{M}$ $\mathrm{NH}_{4} \mathrm{OH}$ (10:6:4:1). This system permits isolation of PC, SM, lyso PC, PI, PS, PE, and PG. The method of Bligh and Dyer (13) was used to extract lipids from the gel and phosphorous content was quantitated by the method of Ames and Dubin (14). The osmium tetroxide method of Mason et al. (15) was utilized to obtain saturated PC. This procedure yields a fraction that upon gas chromatography in our laboratory shows $94-99 \%$ saturated fatty acid components. The method used for isolation of surfactant from total lung is a slightly modified procedure (16) of that originally described by Frosolono et al. (17). Aliquots of lung homogenate were utilized to measure glycogen (19), DNA (20), and protein content (21). Dry to wet ratios were determined on each lung sample, and results were compared in relation to both weights. Gonadal steroids were analyzed by radioimmunoassay $(22,23)$.

Data were analyzed by 2-way analysis of variance with gestational age and sex of fetus as factors; and by regression analysis versus gestational age including linear, quadratic, and cubic trend. Quadratic and cubic trends were used to characterize rate of change. Differences in trend by gender were tested if the overall sex by gestational age interaction was significant at $p=$ 0.10 . Results for lung phospholipids and glycogen were unaltered by use of alternative reference bases such as dry lung weight or DNA content.

In additional attempts to uncover potential differences in lung development between male and female fetuses, a combination of predictors were analyzed by all possible subsets regression (BMDP Program PQR) (24). The equation obtained was then applied separately to each fetus and the resultant "maturity index" analyzed.

\section{RESULTS}

Physical growth characteristics of male and female primate fetuses with advancing gestational age are illustrated in Table 1. In all, 29 fetuses of each sex were investigated and the data demonstrate a uniform progression in body weight, crown-rump length, and other growth indices through the last $25 \%$ of rhesus pregnancy. There was no statistically significant difference overall in male and female growth characteristics.

Male fetuses had higher concentrations of testosterone (mean $\pm \mathrm{SEM}=1073 \pm 180$ versus $254 \pm 35 \mathrm{pg} / \mathrm{ml}, p<0.001)$ and dihydrotestosterone $(295=31$ versus $170=15 \mathrm{pg} / \mathrm{ml}, p<0.001)$ than females in serum obtained from umbilical cord vessels. Total estrogens did not differ statistically between fetal sexes (204 $=25 \mathrm{pg} / \mathrm{ml}$ for females versus $161=18 \mathrm{pg} / \mathrm{ml}$ for males).

Absolute concentrations of selected phospholipids are presented in Table 2 and concentrations of DNA, glycogen, and protein in Table 3. Phospholipid concentrations in whole lung homogenates rose with advancing gestational age. The rate of increase in PC and DSPC accelerated with gestational age $(p=$ 0.001 ). The quantity of $P G$ increased toward term most substantially after 155 days of gestation. There were no statistically discernible differences in biochemical assessment between sexes at any gestational age. As gestation progressed, there was a serial decline in glycogen content $(p<0.0001)$ with relatively stable proportions of sphingomyelin, DNA, and protein. Further, as depicted in Figure 1 , in which $\% V_{10}$ and $V_{\text {Max }}$ or pulmonary distensibility are displayed with advancing gestation there are no perceptible differences between males and females. Surfactant fraction PC and surfactant phosphilid/total phospholipid ratios (Fig. 2), rose significantly at 145 days gestation concomitant with changes in $\% \mathrm{~V}_{10}$ and $\mathrm{V}_{\mathrm{Max}}$.

Table 1. Growth characteristics of primate fetuses*

\begin{tabular}{|c|c|c|c|c|c|c|c|}
\hline $\begin{array}{l}\text { Gestational } \\
\text { age (days) }\end{array}$ & $\begin{array}{c}\operatorname{Sex} \mathrm{M} / \mathrm{F} \\
(n)\end{array}$ & Wt (g) & $\begin{array}{c}\text { Crown-WMP } \\
\text { length }(\mathrm{cm})\end{array}$ & $\begin{array}{c}\text { Placental } \\
\text { wt }\end{array}$ & $\begin{array}{c}\text { Right lung } \\
\text { wt (g wet } \\
\text { wt) }\end{array}$ & $\begin{array}{c}\text { Left wing } \\
\text { wt (g wet } \\
\text { wt) }\end{array}$ & $\begin{array}{l}\text { Lung dry to } \\
\text { wet wt ratio }\end{array}$ \\
\hline $125 \pm 1.0$ & $\begin{array}{l}M(4) \\
F(3)\end{array}$ & $\begin{array}{l}292 \pm 22 \\
284 \pm 24\end{array}$ & $\begin{array}{l}15.9 \pm 0.5 \\
15.2 \pm 0.8\end{array}$ & $\begin{array}{l}118 \pm 20 \\
108 \pm 19\end{array}$ & $\begin{array}{l}3.75 \pm 0.6 \\
2.66 \pm 0.4\end{array}$ & $\begin{array}{l}2.74 \pm 0.4 \\
2.11 \pm 0.1\end{array}$ & $\begin{array}{l}0.16 \pm 0.02 \\
0.14 \pm 0.002\end{array}$ \\
\hline $135 \pm 1.0$ & $\begin{array}{l}\text { M (6) } \\
F(8)\end{array}$ & $\begin{array}{l}343 \pm 49 \\
315 \pm 25\end{array}$ & $\begin{array}{l}16.5 \pm 0.9 \\
16.7 \pm 0.4\end{array}$ & $\begin{array}{l}121 \pm 26 \\
116 \pm 14\end{array}$ & $\begin{array}{l}3.06 \pm 0.6 \\
3.72 \pm 0.3\end{array}$ & $\begin{array}{l}2.43 \pm 0.2 \\
2.69 \pm 0.6\end{array}$ & $\begin{array}{l}0.12 \pm 0.02 \\
0.12 \pm 0.02\end{array}$ \\
\hline $144 \pm 1.0$ & $\begin{array}{l}M(7) \\
F(6)\end{array}$ & $\begin{array}{l}378 \pm 49 \\
420 \pm 50\end{array}$ & $\begin{array}{l}17.1 \pm 0.6 \\
18.0 \pm 0.6\end{array}$ & $\begin{array}{l}121 \pm 27 \\
144 \pm 32\end{array}$ & $\begin{array}{l}3.25 \pm 0.6 \\
4.01 \pm 1.3\end{array}$ & $\begin{array}{l}2.62 \pm 0.5 \\
3.08 \pm 1.0\end{array}$ & $\begin{array}{l}0.13 \pm 0.02 \\
0.13 \pm 0.02\end{array}$ \\
\hline $155 \pm 1.0$ & $\begin{array}{l}M(6) \\
F(6)\end{array}$ & $\begin{array}{l}491 \pm 47 \\
416 \pm 74\end{array}$ & $\begin{array}{l}18.5 \pm 0.7 \\
17.6 \pm 1.6\end{array}$ & $\begin{array}{l}137 \pm 16 \\
135 \pm 34\end{array}$ & $\begin{array}{l}4.22 \pm 0.7 \\
3.86 \pm 0.5\end{array}$ & $\begin{array}{l}3.48 \pm 0.5 \\
3.09 \pm 0.6\end{array}$ & $\begin{array}{l}0.13 \pm 0.01 \\
0.12 \pm 0.02\end{array}$ \\
\hline 162.0 & $\begin{array}{l}M(6) \\
F(6)\end{array}$ & $\begin{array}{l}525 \pm 60 \\
496 \pm 39\end{array}$ & $\begin{array}{l}19.2 \pm 0.3 \\
18.8 \pm 1.5\end{array}$ & $\begin{array}{l}182 \pm 33 \\
154 \pm 15\end{array}$ & $\begin{array}{l}4.46 \pm 1.2 \\
4.06 \pm 0.7\end{array}$ & $\begin{array}{l}3.67 \pm 1.1 \\
2.95 \pm 0.3\end{array}$ & $\begin{array}{l}0.12 \pm 0.01 \\
0.14 \pm 0.01\end{array}$ \\
\hline
\end{tabular}

\footnotetext{
* Data are reported as means \pm SD for no. of fetal animals given in parentheses.
} 
Table 2. Concentrations of selected lung phospholipids*

\begin{tabular}{|c|c|c|c|c|c|c|}
\hline \multirow{2}{*}{$\begin{array}{l}\text { Gestation } \\
\text { age group }\end{array}$} & & \multicolumn{4}{|c|}{$\mu \mathrm{mol} / \mathrm{g}$ wet $\mathrm{wt}$} & \multirow[b]{2}{*}{$\mathrm{DSPC} / \mathrm{PC}(\%)$} \\
\hline & & $\mathrm{PC}$ & DSPC & PG & Sphingomyelin & \\
\hline \multirow[t]{2}{*}{125} & M & $5.43 \pm 0.7$ & $1.55 \pm 1.1$ & $0.06 \pm 0.04$ & $2.16 \pm 0.21$ & $29.0 \pm 4.2$ \\
\hline & $\mathrm{F}$ & $6.71 \pm 0.5$ & $1.63 \pm 0.2$ & $0.16 \pm 0.05$ & $2.28 \pm 0.28$ & $24.2 \pm 1.8$ \\
\hline \multirow[t]{2}{*}{135} & M & $5.59 \pm 1.1$ & $1.69 \pm 0.7$ & $0.01 \pm 0.02$ & $1.99 \pm 0.90$ & $30.4 \pm 9.4$ \\
\hline & $\mathrm{F}$ & $5.23 \pm 0.7$ & $1.51 \pm 0.3$ & $0.03 \pm 0.02$ & $1.63 \pm 0.22$ & $29.1 \pm 5.9$ \\
\hline \multirow[t]{2}{*}{145} & M & $7.69 \pm 2.3$ & $2.80 \pm 1.6$ & $0.08 \pm 0.08$ & $1.70 \pm 0.45$ & $35.0 \pm 12$ \\
\hline & $\mathrm{F}$ & $5.68 \pm 2.0$ & $2.36 \pm 0.7$ & $0.13 \pm 0.14$ & $1.60 \pm 0.20$ & $42.0 \pm 3.7$ \\
\hline \multirow[t]{2}{*}{155} & M & $9.70 \pm 3.5$ & $4.63 \pm 2.0$ & $0.15 \pm 0.24$ & $1.55 \pm 0.22$ & $46.5 \pm 5.4$ \\
\hline & $\mathrm{F}$ & $10.34 \pm 4.9$ & $4.67 \pm 1.9$ & $0.11 \pm 0.12$ & $1.57 \pm 0.23$ & $47.2 \pm 9.1$ \\
\hline \multirow[t]{2}{*}{162} & M & $12.28 \pm 3.0$ & $6.40 \pm 2.0$ & $0.27 \pm 0.26$ & $2.09 \pm 0.63$ & $52.8 \pm 8.4$ \\
\hline & $\mathrm{F}$ & $12.18 \pm 2.9$ & $6.39 \pm 1.2$ & $0.26 \pm 0.16$ & $2.01 \pm 0.52$ & $53.3 \pm 7.8$ \\
\hline
\end{tabular}

* Data are reported as means \pm SD for $(n)$ of fetal animals listed in Table 1 .

Table 3. Glycogen, DNA, and protein content in fetal primate

\begin{tabular}{clrcc}
\multicolumn{5}{c}{ lungs* } \\
\hline $\begin{array}{c}\text { Gestational } \\
\text { Age Group }\end{array}$ & & $\begin{array}{c}\text { DNA } \\
\text { (mg/g wet wt) }\end{array}$ & $\begin{array}{c}\text { Glycogen } \\
(\mathrm{mg} / \mathrm{g} \text { wet wt })\end{array}$ & $\begin{array}{c}\text { Protein } \\
(\mathrm{mg} / \mathrm{g} \text { wet wt })\end{array}$ \\
\hline 125 & M & $9.38 \pm 3.13$ & $13.9 \pm 3.8$ & $72.87 \pm 5.46$ \\
& F & $10.80 \pm 3.36$ & $10.4 \pm 2.4$ & $81.78 \pm 1.47$ \\
135 & M & $7.38 \pm 1.87$ & $8.0 \pm 3.4$ & $64.34 \pm 10.4$ \\
& F & $9.38 \pm 1.38$ & $7.1 \pm 2.0$ & $68.09 \pm 13.4$ \\
145 & M & $8.52 \pm 7.93$ & $4.8 \pm 1.7$ & $69.88 \pm 8.15$ \\
& F & $9.76 \pm 4.17$ & $5.4 \pm 1.9$ & $68.74 \pm 9.33$ \\
& & & & \\
155 & M & $9.29 \pm 0.64$ & $3.5 \pm 1.7$ & $56.61 \pm 13.9$ \\
& F & $8.43 \pm 1.22$ & $2.4 \pm 0.4$ & $63.30 \pm 7.53$ \\
& & & & \\
162 & M & $7.37 \pm 1.96$ & $1.5 \pm 1.0$ & $72.34 \pm 5.27$ \\
& F & $10.27 \pm 1.85$ & $2.4 \pm 0.9$ & $74.39 \pm 11.5$ \\
\hline
\end{tabular}

* Data are reported as means \pm SD for $(n)$ of fetal animals listed in Table 1 .

The "best fit" equation for compiling a maturity index based on multiple measured factors was: $\mathrm{GA}=175+5.27 \mathrm{~V}_{\mathrm{Max}}+1.05$ DSPC -1.55 glycogen -0.236 protein. There was no significant sex by gestational age interaction or overall difference by sex for the given sample size $(p=>0.5)$. Also, the numerical differences noted between males and females at 125 days gestation was not evident statistically $(p>0.01)$ (Table 4$)$.

\section{DISCUSSION}

Regardless of confirmed clinical evidence for gender related differences in postnatal mortality associated with neonatal respiratory disease (2), the pathogenesis of this discordance remains controversial. Results from investigations regarding prenatal aspects of lung maturation in the normal pregnancy and gestations in which the fetus has been exposed to exogenous hormones such as corticosteroids have been inconsistent. For example, it should be noted that in a nonhuman primate model of RDS, Truog et al. (5) recorded that newborn female Macaca nemistrena (delivered between 134 and 150 days gestation) had more severe clinical indices of respiratory distress, lower lung lavage fluid phospholipids, lower lavage fluid/whole lung homogenate phospholipid ratios and less surface activity of lavage fluid than their male counterparts. Although the study included 44 animals, the gestational age at delivery encompassed a wide spectrum negating statistical evaluation of animals grouped at discrete time points in pregnancy.

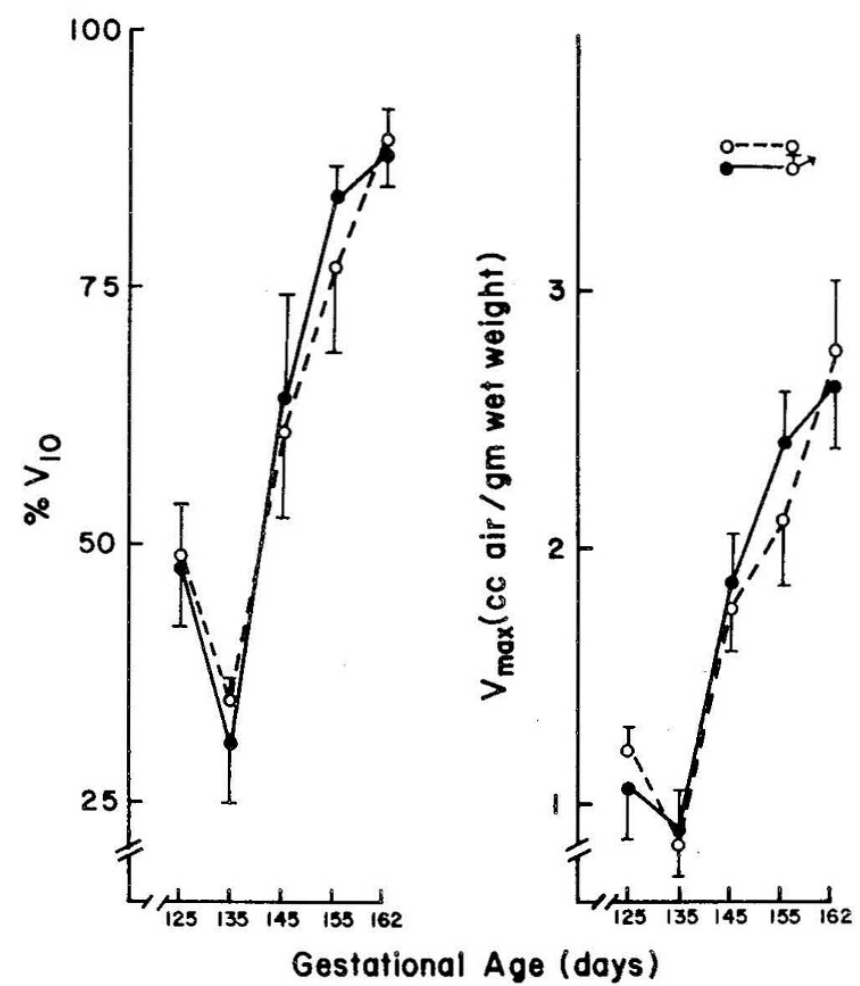

Fig. 1. Physiologic assessment of lung maturation in male (solid line) and female (dotted line) primate fetuses with advancing gestation (mean $=\mathrm{SEM}$ for $n$ animals listed in Table 1). \% $\mathrm{V}_{10}$ represents that portion of total lung capacity remaining during a pressure-volume study on deflation to $10 \mathrm{~cm} \mathrm{H}_{2} \mathrm{O}$ and $\mathrm{V}_{\mathrm{Max}}$ reflects the maximum volume per $\mathrm{g}$ of wet lung at $30 \mathrm{~cm} \mathrm{H}_{2} \mathrm{O}(18)$. The mean $\mathrm{V}_{\mathrm{Max}}$ and $\% \mathrm{~V}_{10}$ between 125 and 135 days gestation are not statistically different, analysis of overall changes in $\mathrm{V}_{\text {Max }}$ and $\% \mathrm{~V}_{10}$ indicate a significant increasing linear trend with time $(p<0.0001)$.

In general, studies to date have involved polytocous short gestation species (e.g. rats and rabbits) and not animal models with considerably longer singleton pregnancies more comparable to humans. Although the nature (i.e. progression) of pulmonary maturation may not be fundamentally different in short gestation species, the timing and rate of sequential changes in macaques more closely mimics the human developmental process (25). Additionally, sufficient lung tissue is available from each fetal animal for multidisciplinary and comprehensive assessment. Cesarean section delivery between 125 days gestation and term was chosen since lungs from nonhuman primates before 135 days 
are clearly immature by all criteria and absolute concentrations of phospholipids are quite uniform (26-28). Also, the latter gestational age range corresponds to the late cannicular and sacular phase of lung development when gender related differences in human neonates are readily detectable (2).

In a recent investigation, Nielsen et al. (8) administered DHT to pregnant rabbits and observed a dose-related blunting of the sex-associated difference in indices of fetal surfactant production when compared to controls. The latter findings resulted from a lowering of disaturated $\mathrm{PC} /$ sphingomyelin ratios in lung lavage fluid from female fetuses to the male level. When the antiandrogen flutamide was substituted for DHT and the experiments repeated, the gender related differences in lung lavage disaturated $\mathrm{PC} /$ sphingomyelin ratio was equalized by elevation of the male ratio to that of females. Giannopoulos and Smith (29), after assessment of androgen receptors in fetal rabbit lungs, hypothesized that the male disadvantage regarding fetal lung development does not appear to be related to a difference in the concentration of pulmonary androgen receptors but rather may be due in part to increased levels of circulating androgens. There is a marked sex difference in fetal rhesus testosterone levels from day 40 of gestation until term; however, the differences are maximal before day 100 (30-33). Consequently, if endogenous androgens affect the progression of fetal lung surfactant biosynthesis, a differential effect between males and females should have been detected at the gestational ages assessed in the current study. This was not the case despite the fact that male fetuses in the present

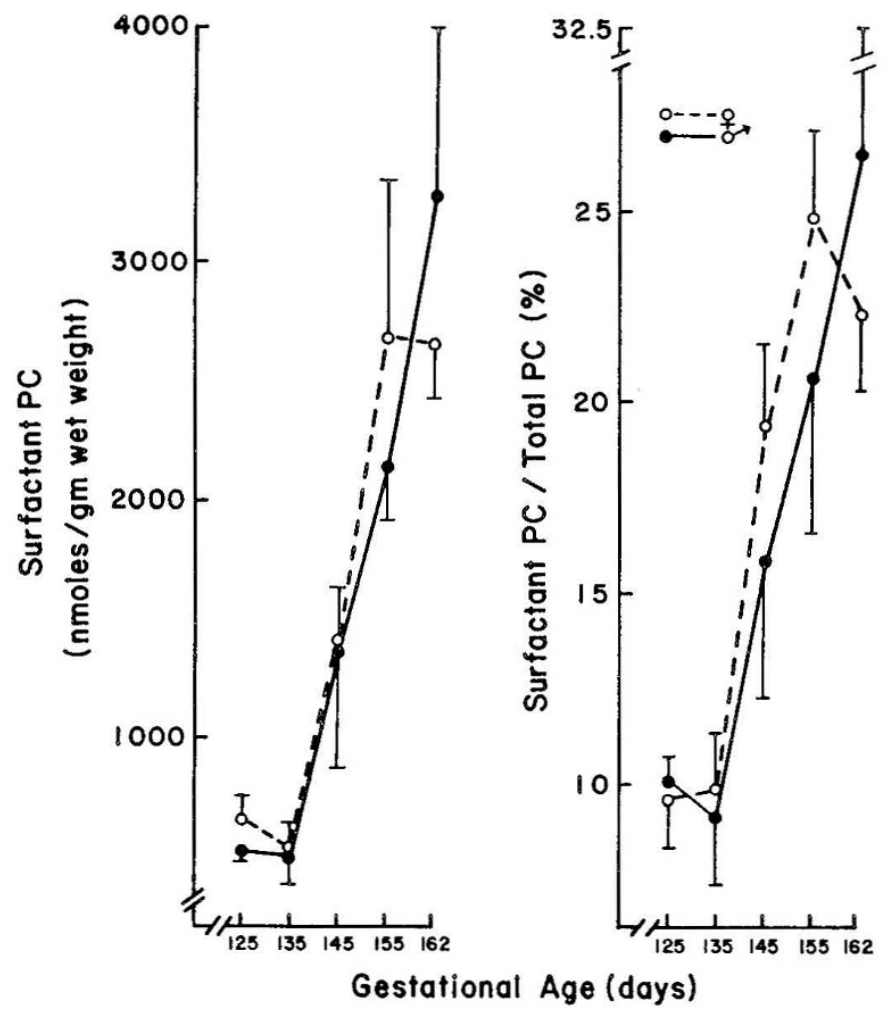

Fig. 2. Surfactant fraction $P C$ and surfactant $P C /$ total $P C$ ratio (mean $+\mathrm{SEM}$ ) in male (solid line) and female (dotted line) primate fetuses with advancing gestation. study had higher levels of both testosterone and DHT than females, while fetal estrogen values did not differ between genders.

Additionally, others $(6,7)$ have been unable to detect differences in the biosynthesis of lung phospholipids between male and female fetuses which raises the possibility that the sex-related disparity in RDS incidence and mortality may be accounted for by as yet undelineated differences in intracellular transport or secretion of surfactant.

In addition to the standard biochemical approach used to quantitate phospholipids in whole lung tissue, we have assessed surfactant fraction PC concentration which has been implicated as a sensitive and specific indicator of fetal maturation (9). Indeed, the quantitative change in surfactant fraction PC concentration for both sexes was considerably greater than that observed for whole lung PC between 135 days gestation and term (5.7- versus 2.3-fold). Further, the increase in surfactant PC occurred in association with improving lung distensibility and deflation stability prior to maximal changes in whole lung DSPC or PC concentrations.

Applying these techniques in this investigation of 58 rhesus monkeys, we have been unable to demonstrate a discordance in fetal lung development between males and females during the last trimester of rhesus gestation by analysis of lung biochemistry, surfactant fraction phospholipids, and physiologic indices of functional integrity. The data reveal a parallel and equivalent progression in pulmonary maturation without evidence of significant gender-related differences at any of the five gestational ages assessed. To our knowledge, these are the most extensive data accumulated to date in the nonhuman primate. However, it is possible that differences in fetal lung maturation exist which are too small to be detected within the current sample. To avoid a type II error, the data therefore remain suggestive rather than confirmatory. Where slight differences in the means for selected measured variables exist (i.e. DSPC/PC ratio at 145 days gestation), projections of the number of animals required to reach statistical significance at a minimum acceptable power of $80 \%$ would require at least tripling the sample size at multiple gestational ages. To improve the sensitivity of the study, an attempt was made to combine several variables by subset regression analysis into a "maturity index" which improved the power of the observations without effect on determination of genderrelated differences.

Based on in vitro experiments utilizing fetal rat lung cell cultures, Torday (4) has suggested that there are sex differences in both cortisol metabolism and fibroblast pneumonocyte factor production by the fetal lung fibroblast which may mediate gender-related differences in pulmonary surfactant biosynthesis. While these data emphasize the importance of lung mesenchyme and epithelium interaction during pulmonary development, the uniformity of our results do not support a differential effect between sexes. The process of lung differentiation and maturation is complex and is influenced in vivo by multiple interactive mechanisms. A variety of hypotheses could conceivably account for the observed differences in postnatal RDS incidence and mortality between males and females (2). Differences in lung structures between male and female fetuses during a narrow portion of gestation (34) may alter the interaction with nonsurfactant protein compounds $(35,36)$ or hormones $(37,38)$ with respect to the recovery process and survival from RDS.

Table 4. Means and SD of "lung maturity index" by gestational age and sex

\begin{tabular}{|c|c|c|c|c|c|c|c|c|c|c|c|}
\hline & \multicolumn{2}{|r|}{125} & \multicolumn{2}{|r|}{135} & \multicolumn{2}{|r|}{145} & \multicolumn{2}{|r|}{155} & \multicolumn{2}{|r|}{162} & \multirow[b]{2}{*}{ Overall } \\
\hline & $n$ & Mean (SD) & $n$ & Mean (SD) & $n$ & Mean (SD) & $n$ & Mean (SD) & $n$ & Mean (SD) & \\
\hline Male & 4 & $125.9(7.4)$ & 5 & $134.9(4.3)$ & 7 & $146.4(5.5)$ & 5 & $154.7(5.1)$ & 5 & $159.1(5.1)$ & $145.1(12.8)$ \\
\hline Female & 3 & $130.1(4.0)$ & 6 & $136.9(1.8)$ & 5 & $144.4(1.2)$ & 5 & $154.6(5.2)$ & 5 & $158.4(3.8)$ & $145.8(10.7)$ \\
\hline
\end{tabular}


Acknowledgments. The authors are grateful to R. D. Zachman for critical comments and Ms. Mary Maxwell for clerical assistance.

\section{REFERENCES}

1. Perelman RH, Farrell PM 1982 Analysis of causes of neonatal death in the United States with specific emphasis on fatal hyaline membrane disease. Pediatrics 70:570-575

2. Perelman RH, Palta M, Kirby R, Farrell PM 1986 Discordance between male and female deaths due to the respiratory distress syndrome. Pediatrics $78: 238-244$

3. Nielsen HC, Torday JS 1985 Sex differences in avian embryo pulmonary surfactant production: evidence for sex chromosome involvement. Endocrinol 117:31-37

4. Torday JS 1984 The sex difference in Type II cell surfactant: synthesis originates in the fibroblast in vitro. Exp Lung Res 7:187-194

5. Truog WE, Kessler DL, Palmer S, Murphy J, Woodrum DE, Hodson WA 1981 Differential effect of sex in experimental hyaline membrane disease in newborn monkeys. Am Rev Respir Dis 124:435-439

6. Khosla SS, Brehier A, Eisenfeld AJ, Ingelson LD, Parks PA, Rooney SA 1983 Influence of sex hormones on lung maturation in the fetal rabbit. Biochem Biophys Acta 750:112-126

7. Freese WB, Hallman M 1983 The effect of betamethasone and fetal sex on the synthesis and maturation of lung surfactant phospholipids in rabbits. Biochem Biophys Acta 750:47-59

8. Nielsen HC, Zinman HM, Today JJ 1982 Dihyarotestosterone inhibits fetal rabbit pulmonary surfactant production. J Clin Invest 69:611-616

9. Rieutort M, Farrell PM, Engle MJ, Pignol B, Bourbon JR 1986 Changes in surfactant phospholipids in fetal rat lungs from normal and diabetic pregnancies. Pediatr Res 20:650-654

10. Kemnitz JW, Houser WD, Eisele SG, Engle MJ, Perelman RH, Farrell PM 1984 Pregnancy and fetal development in the rhesus monkey. I. Maternal metabolism and fetal growth. In: Nathanielsz PW, Parer JT (eds) Research in Perinatal Medicine. Perinatology Press, New York, pp 2-25

11. Perelman RH, Engle MJ, Kemnitz JW, Kotas RV, Farrell PM 1982 Biochemical and physiological development of fetal rhesus lung. J Appl Physio 53:230-235

12. Radin NS 1979 Preparation of lipid extracts methods. Enzymology 14:245254

13. Bligh EG, Dyer WJ 1959 A rapid method of total lipid extraction and purification. Can J Biochem Physiol 37:911-917

14. Ames BN, Dubin DT 1960 The role of polyamines in the neutralization of bacteriophage deotyribonucleic acid. J Biol Chem 235:769-775

15. Mason RJ, Nellenbogen J, Clements JA 1976 Isolation of disaturated phosphatidylcholine with osmium tetroxide. J Lipid Res 17:281-284

16. Engle MJ, Sanders RL, Douglas WHJ 1980 Type II alveolar cells in organotypic culture: model system for the study of surfactant synthesis. Biochim Biophys Acta 717:225-236

17. Frosolono MF, Charms BL, Pawlowski R, Silvka S 1970 Isolation, characterization and surface chemistry of a surface-active traction from dog lung. J Lipid Res 2:439-457

18. Engle MJ, Perelman RH, Kemnitz JW, Farrell PM 1984 Pregnancy and fetal development in the rhesus monkey. II. Fetal lung maturation. In: Nathanielsz PW, Parer JT (eds) Research in Perinatal Medicine. Perinatology Press, New
York, pp 28-53

19. Lo S, Russel JC, Taylor AW 1970 Determination of glycogen in small tissue samples. J Appl Physiol 28:234-236

20. Giles KW, Myers A 1965 Improved diphenylamine method for the estimation of deoxyribonucleic acid. Nature 206:93

21. Hartree EF 1972 A modification of the Lowry method that gives a linear photometric response. Anal Biochem 48:422-427

22. Sholl SA, Robinson JA, Wolf RE 1979 Estrone, 17-estradiol, and cortisol in serum of peripartum rhesus monkeys. Endocrinology 104:1274-1278

23. Robinson JA, Scheffler G, Eisele S, Goy RW 1975 Effects of age and season on the sexual behavior and plasma testosterone and dihydrotestosterone concentrations of laboratory housed male rhesus monkeys. Biol Reprod 13:203-210

24. Dixon WJ, Brown MB, Engelman L, Frane JW, Hill MA, Jennrich RI, Toporek JD 1983 BMDP statistical software. University of California Press, Berkeley, CA

25. Farrell PM 1982 Morphologic aspects of lung maturation. In: Farrell PM (ed) Lung Development: Biological and Clinical Perspectives, Vol I. Academic Press, New York pp 13-24

26. Hodson WA, Palmer AS, Blakely GA, Murphy JA, Woodron DE, Morgan TE 1977 Lung development in the fetal primate, macaca nemestrina I. Growth and compositional changes. Pediatr Res 11:1009-1014

27. Palmer S, Morgan TE, Prueitt JL, Murphy JH and Hodson WA 1977 Lung development in the fetal primate, Macaca nemestrina II. Pressure-volume and phospholipid changes. Pediatr Res 11:1057-1063

28. Kotas RV, Farrell PM, Ulane RE, Chez RA 1977 Fetal rhesus monkey lung development: lobar differences and discordances between stability and distensibility. J Appl Physiol 43:92-98

29. Giannopoulos G, Smith SKS 1982 Androgen receptors in fetal rabbit lung and the effect of fetal sex on the levels of circulating hormones and pulmonary hormone receptors. J Steroid Biochem 17:461-465

30. Resko JA 1975 Fetal hormones and their effect on the differentiation of the central nervous system in primates. Fed Proc 34:1650-1655

31. Resko JA, Malley A, Begley D, Hess DL 1973 Radioimmunoassay of testosterone during fetal development of the rhesus monkey. Endocrinology 93:156-160

32. Ellinwood WE, Brennan RM, Hess DL, Resko JA 1980 Testosterone synthesis in rhesus fetal testes: comparison between middle and late gestation. Biol Reprod 22:955-963

33. Resko JA, Ellinwood WE, Pasztor LM, Buhl AE 1980 Sex steroids in the umbilical circulation of fetal rhesus monkeys from the time of gonadal differentiation. J Clin Endocrinol Metab 50:900-905

34. Adamson IYR, King EM 1984 Sex-related differences in cellular composition and surfactant synthesis of developing fetal rat lungs. Am Rev Respir Dis 129:130-134

35. Ikegami M, Jobe A, Jacobs H, Lam R 1984 A protein from airways of premature lambs that inhibits surfactant function. J Appl Physiol 57:11341142

36. Jobe A, Ikegami M, Jacobs H, Jones S, Conaway D 1983 Permeability of premature lamb lungs to protein and the effect of surfactant on that permeability. J Appl Physiol 55:169-176

37. Mendelson CR, Johnson MJ, MacDonald PC, Snyder JM 1981 Multihormonal regulation of surfactant synthesis by human fetal lung in vitro. J Clin Endocrinol Metab 53:307-317

38. Snyder JM, Mendelson CF, Johnston JM 1981 The effect of cortisol on rabbit fetal lung maturation in vitro. Dev Biol 85:129-140 